\title{
Food insecurity and diabetes self-management among food pantry clients
}

\author{
Matthew M Ippolito ${ }^{1, *}$, Courtney R Lyles ${ }^{2,3}$, Kimberly Prendergast ${ }^{4}$, \\ Michelle Berger Marshall ${ }^{4}$, Elaine Waxman ${ }^{5}$ and Hilary Kessler Seligman ${ }^{2,3}$ \\ 'Johns Hopkins University School of Medicine, Department of Medicine, 1830 East Monument Street, \\ Room 450B, Baltimore, MD 21287, USA: University of California San Francisco, Department of Medicine, \\ San Francisco, CA, USA: ${ }^{3}$ Center for Vulnerable Populations at San Francisco General Hospital, San Francisco, \\ CA, USA: ${ }^{4}$ Feeding America, Chicago, IL, USA: ${ }^{5}$ Urban Institute, Washington, DC, USA
}

Submitted 18 November 2015: Final revision received 3 May 2016: Accepted 7 June 2016: First published online 13 July 2016

\begin{abstract}
Objective: To examine the association between level of food security and diabetes self-management among food pantry clients, which is largely not possible using clinic-based sampling methods.

Design: Cross-sectional descriptive study.

Setting: Community-based food pantries in California, Ohio and Texas, USA, from March 2012 through March 2014.

Subjects: Convenience sample of adults with diabetes queuing at pantries ( $n$ 1237; $83 \%$ response). Sampled adults were stratified as food secure, low food secure or very low food secure. We used point-of-care glycated $\mathrm{Hb}\left(\mathrm{HbA}_{1 \mathrm{c}}\right)$ testing to determine glycaemic control and captured diabetes self-management using validated survey items.

Results: The sample was $70 \%$ female, $55 \%$ Latino/Hispanic, 25\% white and $10 \%$ black/African American, with a mean age of 56 years. Eighty-four per cent were food insecure, one-half of whom had very low food security. Mean $\mathrm{HbA}_{1 \mathrm{c}}$ was $8.1 \%$ and did not vary significantly by food security status. In adjusted models, verylow-food-secure participants, compared with both low-food-secure and food-secure participants, had poorer diabetes self-efficacy, greater diabetes distress, greater medication non-adherence, higher prevalence of severe hypoglycaemic episodes, higher prevalence of depressive symptoms, more medication affordability challenges, and more food and medicine or health supply trade-offs.

Conclusions: Few studies of the health impact of food security have been able to examine very low food security. In a food pantry sample with high rates of food insecurity, we found that diabetes self-management becomes increasingly difficult as food security worsens. The efficacy of interventions to improve diabetes selfmanagement may increase if food security is simultaneously addressed.
\end{abstract}

\author{
Keywords \\ Food security \\ Food pantries \\ Diabetes self-management
}

Diabetes mellitus disproportionately affects low-income Americans, who experience higher disease prevalence and complication rates ${ }^{(1-3)}$. Food insecurity is one mechanism by which low income may increase risk of poor diabetes outcomes $^{(4)}$. Food insecurity refers to limited or uncertain access to adequate food at the level of the household ${ }^{(5)}$. It is an independent risk factor for poor intermediate health outcomes, including glycaemic control, in adults with diabetes $^{(6-8)}$. Food insecurity may impact diabetes selfmanagement through varied mechanisms: reliance on inexpensive, shelf-stable foods which are generally poor for glycaemic control; binge eating when food becomes available; competing demands between food and healthcare expenditures; and reduced capacity to manage the complexity of diabetes self-care when confronted with the immediacy of inadequate food ${ }^{(4,9)}$.

Food insecurity is categorized by degree of severity: low food security or very low food security ${ }^{(5)}$. Low-food-secure households generally experience diets that are reduced in quality or variety, while very-low-food-secure households also experience reduced food intake ${ }^{(10)}$. In 2012, 14.5\% of US households (33 million adults) were food insecure, of which $8.8 \%$ met criteria for low food security and an additional $5.7 \%$ for very low food security ${ }^{(10)}$. Low and very low food security may differ in ways that are important for diabetes self-management ${ }^{(11-13)}$. For example, adults from very-low-food-secure households are more likely than those from low-food-secure households to have disrupted food 
supplies, including going hungry, reducing food intake and losing weight ${ }^{(10)}$.

Although previous studies have examined food security and diabetes self-management, these studies have generally lacked adequate numbers of very-low-food-secure participants to permit stratified analysis by severity of food insecurity $^{(14,15)}$. As part of a pilot study of food pantry-based interventions for diabetes support ${ }^{(16)}$, we were able to reach a large number of very-low-food-secure individuals who are historically under-represented in clinic-based samples. The high prevalence of very low food security allowed us to examine the differential impact of low and very low food security on diabetes self-management.

\section{Methods}

\section{Study design}

We conducted a cross-sectional survey of adults with diabetes at food pantries in Sonoma County, California, Columbus, Ohio and Corpus Christi, Texas, USA. Baseline surveys for a diabetes self-management intervention located at the food pantries were administered between March 2012 and March 2014. Inclusion criteria included age $\geq 18$ years; English or Spanish language fluency; and point-of-care glycated $\mathrm{Hb}\left(\mathrm{HbA}_{1 \mathrm{c}}\right)$ percentage greater than or equal to $6.5 \%$, or self-reported diagnosis of diabetes with prescription bottles of oral hypoglycaemic medications or insulin on-hand. Point-of-care $\mathrm{HbA}_{1 \mathrm{c}}$ testing was performed with Bayer A1CNow ${ }^{\circledR}$ testing kits. Exclusion criteria included pregnancy, hearing impairment and cognitive impairment. Trained bilingual staff conducted the survey in person (58\%) or over the telephone (42\%) in the participants' preferred language.

\section{Measures}

Food security status was determined using the six-item short form of the US Department of Agriculture's Household Food Security Survey Module ${ }^{(10)}$. By convention, we categorized participants as food secure if they affirmed zero or one item, low food secure if affirming two to four items, and very low food secure if five or six items were affirmed.

We examined eight indicators of diabetes self-management: (i) $\mathrm{HbA}_{1 \mathrm{c}}$; (ii) diabetes self-efficacy; (iii) diabetes distress; (iv) medication non-adherence; (v) severe hypoglycaemia; (vi) depressive symptoms; (vii) medication affordability; and (viii) food-medicine purchasing trade-offs.

Self-efficacy describes an individual's cognitive perception of his/her ability to actively manage his/her chronic disease. Previous studies have linked self-efficacy to diabetes self-care behaviours and glycaemic control ${ }^{(17-20)}$. We measured self-efficacy using an eight-item instrument ${ }^{(21)}$ and calculated mean scores from Likert response options (range of 1-10). A higher score indicates greater self-efficacy, which is generally correlated with lower $\mathrm{HbA}_{1 \mathrm{c}}$ values ${ }^{(21)}$.
Diabetes distress, a measure of the emotional burden an individual associates with managing her/his disease, is independently associated with glycaemic control ${ }^{(22,23)}$. We assessed diabetes distress using a two-item screening tool $^{(24)}$. We averaged scores of the two six-point Likert items to generate a summary score between 1 and 6, with a higher score indicating greater distress.

We assessed medication non-adherence using the fouritem Medication Adherence Questionnaire, with Likert response options from 0 to $4^{(25,26)}$. A higher score indicates lower adherence.

Hypoglycaemia is associated with food insecurity and is often indicative of poor diabetes self-management ${ }^{(15,27)}$. We dichotomized (' 0 times' or ' $\geq 1$ time') responses to the following item: 'In the past 4 weeks, how many times have you had a severe low blood sugar reaction, such as passing out or needing help to treat the reaction?'

Several studies have linked depression to poor glycaemic control and diabetes self-care ${ }^{(28-30)}$. We used the Patient Health Questionnaire-2 (PHQ-2) to assess depressive symptoms. Participants who answered affirmatively to one or both items were considered to have depressive symptoms.

We assessed participants' ability to afford medications with the following item: 'In the last 12 months, how often did you take less medicine than you were supposed to because you could not afford to buy more?'

We considered participants to have made trade-offs between food and medications or diabetes supplies if they answered any of the following four items affirmatively ('often' or 'sometimes' on a four-point Likert scale of 'often', 'sometimes', 'rarely' or 'never'), queried over the last 12 months: 'How often have you ...' (i) '...put off buying food so that you would have money to buy medicines?', (ii) '... put off buying medicines so that you would have money to buy food?', (iii) '... put off buying diabetes supplies, like test strips or lancets, so that you would have money to buy food?' and (iv) '... put off buying food so that you would have money to buy diabetes supplies, like test strips or lancets?'

We measured five covariates, including age, gender, race/ethnicity, education and study site. We assessed race/ ethnicity in order to capture the diversity of our sample and to adjust for known racial/ethnic differences in item response distribution for some of our variables ${ }^{(1,19)}$. Race/ ethnicity was determined by participant selection of 'Latino or Hispanic', 'White', 'Black or African American', 'Native American', 'Asian/Pacific Islander' or 'Other'. Due to very small sample sizes for Native American $(n$ 46) and Asian/Pacific Islander ( $n$ 9) participants, we collapsed the variable into 'Latino or Hispanic', 'White', 'Black or African American' and 'Native American, Pacific Islander or other.'

\section{Statistical analysis}

We compared baseline demographic characteristics using $\chi^{2}$ or $t$ tests for categorical and continuous variables, respectively. We analysed unadjusted associations between food 
security status and diabetes variables using $\chi^{2}$ or one-way ANOVA tests. Participants who did not provide responses to question items pertaining to an individual measure were excluded from analysis of that measure, but included in other analyses. We used logistic or linear regression models depending on whether the self-management outcome was categorical or continuous and included age, gender, race/ ethnicity, education and study site as covariates. In a sensitivity analysis, we additionally adjusted for depressive symptoms in all regression models. Statistical analyses were performed using the statistical software package Stata version 12.0 with a significance level of $P=0.05$.

\section{Results}

\section{Study population}

Of 1495 eligible food pantry clients, 1237 provided informed consent and participated in the survey $(83 \%$ response). More than $98 \%$ of the sample responded to all six of the food insecurity items and all respondents answered at least four items. Most of the sample was food insecure, with $42 \%$ reporting low food security and $42 \%$ very low food security. Almost all (98\%) participants identified as having diabetes with point-of-care $\mathrm{HbA}_{1 \mathrm{c}}$ testing were previously aware of a diabetes diagnosis (i.e. few new cases of diabetes were identified). There were statistically significant differences in age, gender, education, race/ethnicity, BMI and tobacco use by level of food insecurity (Table 1). Survey non-response to each of the diabetes self-management measures ranged from $1 \%$ (depressive symptoms) to $7 \%$ (medication non-adherence).

\section{Clinical characteristics}

There was no statistically significant difference in mean $\mathrm{HbA}_{1 \mathrm{c}}$ (Table 1) or percentage of participants with $\mathrm{HbA}_{1 \mathrm{c}}$ level above $8.5 \%$ (data not shown) by level of food security. Mean BMI was greatest among the very-lowfood-secure group and differed significantly from that of the food-secure group $\left(35.0 v .32 .7 \mathrm{~kg} / \mathrm{m}^{2}, P=0.009\right)$. Tobacco use was more than twice as frequent in the very low-food-secure compared with the food-secure group (31\% v. $12 \%, P<0 \cdot 001)$.

\section{Diabetes self-management}

We observed poorer diabetes self-management in the foodinsecure groups compared with the food-secure group. All unadjusted associations examined were statistically significant with $P$ values $<0 \cdot 001$ (Table 2). After adjusting for age, gender, race/ethnicity, education and study site, we found statistically significant associations between food insecurity and seven of the diabetes self-management measures in the very-low-food-secure group and four measures in the low-food-secure group (Table 3; reference group is the food-secure group). Diabetes self-efficacy scores were on average 0.51 units lower $(95 \% \mathrm{CI}-0.85$, -0.17) among very-low-food-secure participants compared with food-secure participants and the mean diabetes distress score was 0.79 points higher $(95 \%$ CI $0.54,1.04)$ in the very-low-food-secure compared with the food-secure group. Compared with food-secure participants, those identified as having very low food security had average medication non-adherence scores 0.31 units higher $(95 \% \mathrm{CI}$ $0 \cdot 12,0.50)$. The adjusted odds of reporting an episode of

Table 1 Sociodemographic characteristics, clinical characteristics and study site distribution of participants: a convenience sample of adults with diabetes receiving food assistance at community-based food pantries in California, Ohio and Texas, USA, March 2012-March 2014

\begin{tabular}{|c|c|c|c|c|c|c|c|c|c|}
\hline & \multirow{2}{*}{\multicolumn{2}{|c|}{ Total ( $n$ 1237) }} & \multicolumn{6}{|c|}{ Food security status } & \multirow[b]{3}{*}{$P$ value } \\
\hline & & & \multicolumn{2}{|c|}{ Secure $(n 201,16 \%)$} & \multicolumn{2}{|c|}{ Low $(n 514,42 \%)$} & \multicolumn{2}{|c|}{ Very low ( $n 522,42 \%)$} & \\
\hline & Mean or $n$ & SD or $\%$ & Mean or $n$ & SD or $\%$ & Mean or $n$ & SD or $\%$ & Mean or $n$ & SD or $\%$ & \\
\hline \multicolumn{10}{|l|}{ Sociodemographic characteristics } \\
\hline Age (years), mean and SD & 56.4 & $12 \cdot 5$ & $61 \cdot 0$ & 13.5 & $56 \cdot 3$ & $12 \cdot 5$ & 54.7 & $11 \cdot 6$ & $<0.001$ \\
\hline Female, $n$ and $\%$ & 869 & 70 & 124 & 62 & 377 & 73 & 368 & 71 & 0.03 \\
\hline Race/ethnicity, $n$ and \% & & & & & & & & & $<0.001$ \\
\hline Latino or Hispanic & 670 & 55 & 112 & 56 & 319 & 63 & 239 & 46 & \\
\hline White & 313 & 25 & 55 & 28 & 97 & 19 & 161 & 31 & \\
\hline Black or African American & 121 & 10 & 12 & 6 & 42 & 8 & 67 & 13 & \\
\hline $\begin{array}{l}\text { Native American, Pacific } \\
\text { Islander or other }\end{array}$ & 124 & 10 & 21 & 11 & 50 & 10 & 53 & 10 & \\
\hline Education, $n$ and \% & & & & & & & & & $<0.001$ \\
\hline$<$ High-school degree/GED & 523 & 30 & 90 & 17 & 252 & 48 & 181 & 34 & \\
\hline High-school degree/GED & 282 & 27 & 48 & 17 & 114 & 40 & 120 & 43 & \\
\hline$>$ High-school degree/GED & 430 & 43 & 63 & 15 & 147 & 34 & 220 & 51 & \\
\hline \multicolumn{10}{|l|}{ Clinical characteristics } \\
\hline $\mathrm{HbA}_{1 \mathrm{c}}(\%)$, mean and SD & $8 \cdot 1$ & $2 \cdot 0$ & $8 \cdot 0$ & 1.9 & $8 \cdot 0$ & 1.9 & 8.2 & $2 \cdot 0$ & 0.65 \\
\hline BMI $\left(\mathrm{kg} / \mathrm{m}^{2}\right)$, mean and SD & $34 \cdot 3$ & 8.5 & $32 \cdot 7$ & 6.9 & $34 \cdot 1$ & 8.5 & $35 \cdot 0$ & $9 \cdot 0$ & 0.009 \\
\hline Tobacco use, $n$ and $\%$ & 261 & 21 & 23 & 12 & 79 & 15 & 159 & 31 & $<0.001$ \\
\hline Study site, $n$ and $\%$ & & & & & & & & & $<0.001$ \\
\hline Sonoma County, California & 456 & 37 & 96 & 21 & 210 & 46 & 150 & 33 & \\
\hline Columbus, Ohio & 186 & 15 & 23 & 12 & 87 & 47 & 76 & 41 & \\
\hline Corpus Christi, Texas & 590 & 48 & 82 & 14 & 216 & 37 & 292 & 49 & \\
\hline
\end{tabular}

GED, General Education Diploma. 
Table 2 Unadjusted associations between food insecurity status and diabetes self-management among a convenience sample of adults with diabetes $(n 1237)$ receiving food assistance at community-based food pantries in California, Ohio and Texas, USA, March 2012-March 2014

\begin{tabular}{|c|c|c|c|c|c|c|c|}
\hline \multirow[b]{3}{*}{ Diabetes self-management variables } & \multicolumn{7}{|c|}{ Food security status } \\
\hline & \multicolumn{2}{|c|}{ Secure } & \multicolumn{2}{|c|}{ Low } & \multicolumn{2}{|c|}{ Very low } & \multirow[b]{2}{*}{$P$ value } \\
\hline & Mean & SD & Mean & SD & Mean & SD & \\
\hline Self-efficacy, scored 1-10 & $7 \cdot 3$ & $2 \cdot 1$ & $7 \cdot 0$ & 1.9 & 6.5 & $2 \cdot 0$ & $<0.001$ \\
\hline Diabetes distress, scored 1-6 & 2.4 & 1.4 & 2.9 & 1.5 & $3 \cdot 3$ & $1 \cdot 6$ & $<0.001$ \\
\hline \multirow[t]{2}{*}{ Medication non-adherence, scored $0-4^{*}$} & 0.9 & 0.9 & $1 \cdot 1$ & $1 \cdot 1$ & $1 \cdot 3$ & $1 \cdot 1$ & $<0.001$ \\
\hline & \multicolumn{2}{|c|}{$\%$} & \multicolumn{2}{|c|}{$\%$} & \multicolumn{2}{|c|}{$\%$} & \\
\hline Severe hypoglycaemic episodes & \multicolumn{2}{|c|}{7} & \multicolumn{2}{|c|}{12} & \multicolumn{2}{|c|}{18} & $<0.001$ \\
\hline Depressive symptoms & \multicolumn{2}{|c|}{49} & \multicolumn{2}{|c|}{62} & \multicolumn{2}{|c|}{82} & $<0.001$ \\
\hline Medication affordability challenges & \multicolumn{2}{|c|}{11} & \multicolumn{2}{|c|}{23} & \multicolumn{2}{|c|}{35} & $<0.001$ \\
\hline Food and medication or supply trade-offs & \multicolumn{2}{|c|}{16} & \multicolumn{2}{|c|}{41} & \multicolumn{2}{|c|}{55} & $<0.001$ \\
\hline
\end{tabular}

*Higher scores indicate poorer medication adherence.

Table 3 Adjusted associations between food insecurity status and diabetes self-management among a convenience sample of adults with diabetes $(n 1237)$ receiving food assistance at community-based food pantries in California, Ohio and Texas, USA, March 2012-March 2014

\begin{tabular}{|c|c|c|c|c|}
\hline \multirow[b]{2}{*}{ Diabetes self-management variables } & \multicolumn{2}{|c|}{ Low food secure $v$. food secure } & \multicolumn{2}{|c|}{ Very low food secure $v$. food secure } \\
\hline & $\beta$ & $95 \% \mathrm{Cl}$ & $\beta$ & $95 \% \mathrm{Cl}$ \\
\hline Diabetes self-efficacy & -0.15 & $-0.47,0.18$ & $-0.51^{*}$ & $-0.85,-0.17$ \\
\hline Diabetes distress & $0.27^{*}$ & $0.03,0.51$ & $0.79^{*}$ & $0.54,1.04$ \\
\hline \multirow[t]{2}{*}{ Medication non-adherence } & 0.11 & $-0.06,0.30$ & $0.31^{*}$ & $0.12,0.50$ \\
\hline & OR & $95 \% \mathrm{Cl}$ & OR & $95 \% \mathrm{Cl}$ \\
\hline Severe hypoglycaemic episodes & 1.39 & $0.75,2.59$ & $2 \cdot 63^{*}$ & $1.42,4.85$ \\
\hline Depressive symptoms & $1.60^{*}$ & $1.13,2.25$ & $4.56^{\star}$ & $3.13,6.65$ \\
\hline Medication affordability challenges & $2.05^{*}$ & $1.23,3.43$ & $3.99^{*}$ & $2.40,6.63$ \\
\hline Food and medication or supply trade-offs & $3.46^{*}$ & $2 \cdot 21,5.42$ & $6 \cdot 71^{*}$ & $4 \cdot 25,10 \cdot 6$ \\
\hline
\end{tabular}

Adjusted for age, gender, race/ethnicity, education and study site.

${ }^{*}$ Denotes the $95 \% \mathrm{Cl}$ does not include the null value.

severe hypoglycaemia among very-low-food-secure participants was 2.6 times greater than among participants who were food secure $(\mathrm{OR}=2 \cdot 63 ; 95 \%$ CI 1.42, 4.85). Both the low- and very-low-food-secure groups had significantly higher odds of having depressive symptoms, experiencing challenges around affordability of medications and diabetes supplies, and making trade-offs between food and medications and medical supplies, compared with their foodsecure counterparts. In a sensitivity analysis, significant associations in Table 3 remained statistically significant after additionally controlling for depressive symptoms, with the exception of diabetes distress in the low-food-secure group and medication non-adherence in the very-low-food-secure group (data not shown).

\section{Discussion}

In this community sample of adults with diabetes seeking assistance at food pantries, we identified many adults living in very-low-food-secure households. Our data suggest a dose-response relationship between severity of food insecurity and barriers to diabetes self-management.

Recruitment from food pantries allowed us to reach participants from very-low-food-secure households who we have been unable to reach easily in clinical settings, including clinical settings traditionally serving vulnerable and marginalized populations ${ }^{(6,27)}$. The discrepancy between food insecurity reports in clinical settings and community-based settings suggests that members of food-insecure households may not access clinical care as regularly as less-food-insecure groups. Interventions to engage marginalized groups in clinical care should focus on this underserved population and food pantries may be an ideal venue.

There is a growing capacity for food banks (which provide food, and often infrastructure, to food pantries which distribute food directly to clients) to conduct this work $^{(31)}$ and our research supports this trend. A number of food banks now employ dietitians and are beginning to deliver health-care support services ${ }^{(31)}$. Our ongoing intervention to provide diabetes self-management support 
through food pantry networks similarly seeks to address this apparent gap in care experienced by food-insecure groups $^{(16)}$. Prescription food programmes, currently being used in some health-care systems, may also be effective interventions in this group ${ }^{(32-34)}$ to assist in providing healthy, diabetes-appropriate foods to low- and very-lowfood-secure patients who are engaged in clinical care. Our findings support the notion that food pantries are well positioned to deliver this type of lifestyle content, rather than relying solely on clinic-based approaches.

Participants from very-low-food-secure households did not have significantly higher $\mathrm{HbA}_{1 \mathrm{c}}$ values (8.2\%) than those from low-food-secure (8.0\%) or food-secure (8.0\%) households. The overall mean $\mathrm{HbA}_{1 \mathrm{c}}$ across the entire study population was $8.1 \%$, almost an entire percentage point greater than the national average $\mathrm{HbA}_{1 \mathrm{c}}$ among people with diabetes $(7 \cdot 2 \%)$ reported in the National Health and Nutrition Examination Survey ${ }^{(35)}$. This may suggest that current clinical interventions to improve glycaemic control in lowincome populations, widespread over the last decade, are not effectively reaching many high-risk adults. Furthermore, we do not yet know whether food-secure, low-food-secure and very-low-food-secure populations will respond to self-management support similarly. Prior studies in clinical settings suggest that food-insecure adults may respond differentially to self-management support ${ }^{(18)}$. Understanding the distinct self-management challenges of food-insecure populations will inform the development and implementation of self-management strategies across the spectrum of food security status.

The high BMI among this population may also be reflective of the unique setting in which the study was conducted: food pantries serving a highly vulnerable population. This finding further highlights the importance of studying community-based populations in order to improve our understanding of very low food security and its tight link to high BMI, depressive symptoms, and other barriers to good health in general and diabetes selfmanagement in particular.

We also found high rates of diabetes distress in our sample, which has been linked to diabetes self-care behaviours and glycaemic control ${ }^{(22,23)}$. The very-low-foodsecure group had a mean distress score $>3$, which has been interpreted as indicative of need for clinical intervention $^{(36)}$. Our findings of the highest distress scores in the very-low-food-secure groups may further signal the low penetration of diabetes support into these high-risk groups.

Similarly, we observed a high frequency of severe hypoglycaemic episodes among the very-low-food-secure group. We suspect this high frequency reflects missed meals which accompany exhaustion of food budgets in the very-low-food-secure household and inadequate training in how to manage diabetes medications in the setting of reduced dietary intake ${ }^{(15,37)}$.

Previous studies of depression and food insecurity have predominantly focused on women's and maternal health ${ }^{(38-42)}$. One study of depression and anxiety in mothers stratified by food security status observed proportions of depressive symptoms of 17,21 and $30 \%$ in the food-secure, low-food-secure and very-low-food-secure groups $^{(42)}$ - substantially lower proportions than we observed in our sample (49, 62 and $82 \%$, respectively). Diabetes and food insecurity are separately associated with depression ${ }^{(29,39,42,43)}$, so the high prevalence we observed is unsurprising and emphasizes the ongoing need for mental health services in this population. The interrelationships among depression, diabetes and food insecurity are complex and interventions directed towards food-insecure populations to address depression and diabetes simultaneously are likely to offer advantages over interventions addressing each in isolation ${ }^{(44)}$.

There are several limitations to the present study. It was a cross-sectional analysis and we therefore cannot infer causality. We were not able to control for all potential confounders, including medical co-morbidities, health literacy, substance use and access to care. Food insecurity is a household-level measure, not an individual measure; however, most adults residing in food-insecure households individually experience the effects of food insecurity. All diabetes self-management measures were selfreported, and some were reported via face-to-face interviews (58\%) and others via telephone ( $42 \%)$, constituting potential sources of bias in our data ${ }^{(45)}$. Finally, the interplay among each of the investigated diabetes selfmanagement measures is presumably more complex than our models can depict.

The present study is important in its ability to characterize the most vulnerable subgroup of food-insecure adults with diabetes. We identified independent associations between food insecurity and barriers to diabetes self-management, with greater food insecurity amplifying these challenges. Diabetes self-management support programmes for this population must address not only diabetes self-care and food affordability, but also low self-efficacy, emotional distress and mental health, and barriers to medication adherence. Non-clinical settings may effectively reach the most food-insecure adults with diabetes.

\section{Acknowledgements}

Financial support: This work was supported by NIH/ NCRR/OD UCSF-CTSI Grant Number KL2 RR024130, AHRQ Career Development Award R00HS022408, and The BristolMyers Squibb Foundation. Research reported in this publication was supported by the National Institute of General Medical Sciences of the National Institutes of Health under award number T32GM066691. The content is solely the responsibility of the authors and does not necessarily represent the official views of the National Institutes of Health. Funders had no role in the design, analysis or writing of this article. Conflict of interest: H.K.S. serves on the board of directors of the S.F.-Marin Food Bank but 
receives no financial support from them. All other authors report no conflict of interest. Authorship: M.M.I. drafted the manuscript and analysed and interpreted data; C.R.L. analysed and interpreted data, provided statistical expertise and critically revised the manuscript; K.P. contributed to project conception and design, acquisition of funding, collection of data and critical revision of the manuscript; E.W. and M.B.M. contributed to project conception and design, acquisition of funding, collection and interpretation of data and critical revision of the manuscript; H.K.S. provided project supervision and contributed to project conception and design, acquisition, analysis and interpretation of data, and manuscript drafting and revision. All authors had complete access to the data. Ethics of buman subject participation: This study was conducted according to the guidelines laid down in the Declaration of Helsinki and all procedures involving human subjects were approved by the Copernicus Group Institutional Review Board. Written informed consent was obtained from all subjects.

\section{References}

1. Gaskin DJ, Thorpe RJ Jr, McGinty EE et al. (2014) Disparities in diabetes: the nexus of race, poverty, and place. $A m J$ Public Health 104, 2147-2155.

2. Robbins JM, Vaccarino V, Zhang H et al. (2005) Socioeconomic status and diagnosed diabetes incidence. Diabetes Res Clin Pract 68, 230-236.

3. Agardh E, Allebeck P, Hallqvist J et al. (2011) Type 2 diabetes incidence and socio-economic position: a systematic review and meta-analysis. Int J Epidemiol 40, 804-818.

4. Seligman HK, Bindman AB, Vittinghoff E et al. (2007) Food insecurity is associated with diabetes mellitus: results from the National Health Examination and Nutrition Examination Survey (NHANES) 1999-2002. J Gen Intern Med 22, 1018-1023.

5. National Research Council (2006) Food Insecurity and Hunger in the United States: An Assessment of the Measure. Washington, DC: The National Academies Press.

6. Seligman HK, Jacobs EA, Lopez A et al. (2012) Food insecurity and glycemic control among low-income patients with type 2 diabetes. Diabetes Care 35, 233-238.

7. Seligman HK \& Schillinger D (2010) Hunger and socioeconomic disparities in chronic disease. $N$ Engl J Med 363, 6-9.

8. Wang EA, McGinnis KA, Fiellin DA et al. (2011) Food insecurity is associated with poor virologic response among HIV-infected patients receiving antiretroviral medications. J Gen Intern Med 26, 1012-1018.

9. Silverman J, Krieger J, Kiefer M et al. (2015) The relationship between food insecurity and depression, diabetes distress and medication adherence among low-income patients with poorly-controlled diabetes. I Gen Intern Med 30 , 1476-1480.

10. Coleman-Jensen A, Nord M, Andrews M et al. (2012) Household Food Insecurity in the United States in 2011. Economic Research Report no. 141. Washington, DC: US Department of Agriculture, Economic Research Service.

11. Anater A, McWilliams R \& Watkin CA (2011) Food acquisition practices used by food-insecure individuals when they are concerned about having sufficient food for themselves and their households. J Hunger Environ Nutr 6, 27-44.

12. Dammann KW \& Smith C (2009) Factors affecting lowincome women's food choices and the perceived impact of dietary intake and socioeconomic status on their health and weight. J Nutr Educ Behav 41, 242-253.

13. Drewnowski A \& Darmon N (2005) Food choices and diet costs: an economic analysis. J Nutr 135, 900-904.

14. Berkowitz SA, Baggett TP, Wexler DJ et al. (2013) Food insecurity and metabolic control among US adults with diabetes. Diabetes Care 36, 3093-3099.

15. Seligman HK, Davis TC, Schillinger D et al. (2010) Food insecurity is associated with hypoglycemia and poor diabetes self-management in a low-income sample with diabetes. J Health Care Poor Underserved 21, 1227-1233.

16. Seligman HK, Lyles C, Marshall MB et al. (2015) A pilot food bank intervention featuring diabetes-appropriate food improved glycemic control among clients in three states. Health Aff (Millwood) 34, 1956-1963.

17. Johnston-Brooks CH, Lewis MA \& Garg S (2002) Self efficacy impacts self-care and $\mathrm{HbA}_{1 \mathrm{c}}$ in young adults with Type I diabetes. Psychosom Med 64, 43-51.

18. Lyles CR, Wolf MS, Schillinger D et al. (2013) Food insecurity in relation to changes in hemoglobin $A_{1 c}$, self-efficacy, and fruit/vegetable intake during a diabetes educational intervention. Diabetes Care 36, 1448-1453.

19. Sarkar U, Fisher L \& Schillinger D (2006) Is self-efficacy associated with diabetes self-management across race/ethnicity and health literacy? Diabetes Care 29, 823-829.

20. Talbot F, Nouwen A, Gingras J et al. (1997) The assessment of diabetes-related cognitive and social factors: the Multidimensional Diabetes Questionnaire. J Behav Med 20, 291-312.

21. Kavanagh DJ, Gooley S \& Wilson PH (1993) Prediction of adherence and control in diabetes. J Behav Med 16, 509-522.

22. Fisher L, Glasgow RE \& Strycker LA (2010) The relationship between diabetes distress and clinical depression with glycemic control among patients with type 2 diabetes. Diabetes Care 33, 1034-1036.

23. Fisher L, Mullan JT, Arean P et al. (2010) Diabetes distress but not clinical depression or depressive symptoms is associated with glycemic control in both cross-sectional and longitudinal analyses. Diabetes Care 33, 23-28.

24. Fisher L, Glasgow RE, Mullan JT et al. (2008) Development of a brief diabetes distress screening instrument. Ann Fam Med 6, 246-252.

25. Krapek K, King K, Warren SS et al. (2004) Medication adherence and associated hemoglobin $\mathrm{A}_{1 \mathrm{c}}$ in type 2 diabetes. Ann Pharmacother 38, 1357-1362.

26. Morisky DE, Green LW \& Levine DM (1986) Concurrent and predictive validity of a self-reported measure of medication adherence. Med Care 24, 67-74.

27. Seligman HK, Jacobs EA, Lopez A et al. (2011) Food insecurity and hypoglycemia among safety net patients with diabetes. Arch Intern Med 171, 1204-1206.

28. Gross R, Olfson M, Gameroff MJ et al. (2005) Depression and glycemic control in Hispanic primary care patients with diabetes. I Gen Intern Med 20, 460-466.

29. Hanson KL \& Olson CM (2012) Chronic health conditions and depressive symptoms strongly predict persistent food insecurity among rural low-income families. J Health Care Poor Underserved 23, 1174-1188.

30. Lustman PJ, Anderson RJ, Freedland KE et al. (2000) Depression and poor glycemic control: a meta-analytic review of the literature. Diabetes Care 23, 934-942.

31. County Health Rankings and Roadmaps (2016) Healthy food initiatives in food banks. http://www.county healthrankings.org/policies/healthy-food-initiatives-food-banks (accessed June 2016).

32. Baronberg S, Dunn L, Nonas C et al. (2013) The impact of New York City's Health Bucks program on electronic benefit transfer spending at farmers markets, 2006-2009. Prev Chronic Dis 10, E163. 
33. Bunnell R, O'Neil D, Soler R et al. (2012) Fifty communities putting prevention to work: accelerating chronic disease prevention through policy, systems and environmental change. J Community Health 37, 1081-1090.

34. Herman DR, Harrison GG, Afifi AA et al. (2008) Effect of a targeted subsidy on intake of fruits and vegetables among low-income women in the Special Supplemental Nutrition Program for Women, Infants, and Children. Am J Public Health 98, 98-105.

35. Centers for Disease Control and Prevention (2014) Mean/ Median A1c Among Adults with Diagnosed Diabetes, United States, 1988-1994 to 1999-2006. http://www.cdc.gov/diabetes/ statistics/a1c/a1c_mean_median.htm (accessed June 2016).

36. Polonsky WH, Fisher L, Earles J et al. (2005) Assessing psychosocial distress in diabetes: development of the diabetes distress scale. Diabetes Care 28, 626-631.

37. Seligman HK, Bolger AF, Guzman D et al. (2014) Exhaustion of food budgets at month's end and hospital admissions for hypoglycemia. Health Aff (Millwood) 33, $116-123$.

38. Corcoran M, Heflin CM, Siefert K et al. (2001) Food insufficiency and the physical and mental health of low-income women. In Welfare, Work, and Wellbeing, pp. 159-177 [MC Lennon, editor]. New York: The Haworth Medical Press.
39. Heflin CM, Siefert K \& Williams DR (2005) Food insufficiency and women's mental health: findings from a 3-year panel of welfare recipients. Soc Sci Med 61, 1971-1982.

40. Siefert K, Heflin CM, Corcoran ME et al. (2001) Food insufficiency and the physical and mental health of lowincome women. Women Health 32, 159-177.

41. Siefert K, Heflin CM, Corcoran ME et al. (2004) Food insufficiency and physical and mental health in a longitudinal survey of welfare recipients.J Health Soc Behav $\mathbf{4 5}$, 171-186.

42. Whitaker RC, Phillips SM \& Orzol SM (2006) Food insecurity and the risks of depression and anxiety in mothers and behavior problems in their preschool-aged children. Pediatrics 118, e859-e868.

43. Anderson RJ, Freedland KE, Clouse RE et al. (2001) The prevalence of comorbid depression in adults with diabetes: a meta-analysis. Diabetes Care 24, 1069-1078.

44. Bogner HR, Morales KH, de Vries HF et al. (2012) Integrated management of type 2 diabetes mellitus and depression treatment to improve medication adherence: a randomized controlled trial. Ann Fam Med 10, 15-22.

45. Glasgow RE, Ory MG, Klesges LM et al. (2005) Practical and relevant self-report measures of patient health behaviors for primary care research. Ann Fam Med 3, 73-81. 